\title{
The creation and circulation of public geographies
}

Dialogues in Human Geography

3(I) 96-102

(C) The Author(s) 2013

Reprints and permission:

sagepub.co.uk/journalsPermissions.nav DOI: 10.1 |77/20438206/3486435

dhg.sagepub.com

(S)SAGE

\section{Rob Kitchin}

National University of Ireland Maynooth, Ireland

\section{Denis Linehan}

University College Cork, Ireland

\section{Cian O'Callaghan}

National University of Ireland Maynooth, Ireland

\section{Philip Lawton}

Maastricht University, Netherlands

\begin{abstract}
In response to the commentaries, we discuss further how social media disrupts and remakes the creation and circulation of geographical knowledges and potentially reconfigures the moral economy of the social sciences. In particular, we examine questions of what is meant by public geography, the publics which such geographies serve, alternative and complementary approaches to social media, the politics of authorship within collective blogs, the politics and mechanisms of knowledge circulation, and the extent to which social media has an impact beyond the academy, enacting 'minimal politics'.
\end{abstract}

\section{Keywords}

authorship, circulation, impact, knowledge, public geography

When we first established the IrelandAfterNAMA blog in late 2009, the members of the collective were, for the most part, new to social media, though not necessarily public geographies. Our motivations were diverse, but we shared a strong sense of dissatisfaction with the way in which the crisis was being represented, analysed and interrogated in Ireland and internationally. As we detail in our paper (Kitchin et al., 2013), our early interventions involved a series of missteps, challenges and pitfalls as well as opportunities, rewards and illuminations. Nevertheless, blogging as Gibson and Gibbs (2013) note in reference to their own experience, offered us a way of " "cutting through" to new and unknown audiences' that has caused us to (as Graham, 2013, also asserts) change what we think it means to be geographers and academics. As one colleague said - when surprised by the intense and immediate public

\section{Corresponding author:}

Rob Kitchin, NIRSA, National University of Ireland Maynooth, Maynooth, County Kildare, Ireland.

Email: rob.kitchin@nuim.ie 
response to her post - 'So this is what it feels like to have your work read?. Whilst our engagements with social media placed us by no means on terra incognita, it was equally clear that we were not on terra firma. The media landscape and its social and political context was shifting fast and academics, amongst other groups, were experimenting with new ways of both situating themselves within these emergent assemblages and resolving some of the issues thrown up by doing academic work in this fashion. The six commentaries responding to our paper testify to these unfolding processes. Taken together, they raise a number of critical points concerning the disposition of IrelandAfterNama and academic practices, public geographies and social media more generally. The diversity of the issues they raise demonstrate the need to think through the impact social media is having on geography (public or otherwise). Here, we engage with their most salient arguments, focusing on how social media disrupts and remakes the creation and circulation of geographical knowledges and potentially reconfigures the moral economy of the social sciences.

\section{The politics of creating public geographies}

Together the six commentaries raise a number of questions and points concerning the creation of public geographies in terms of what is meant by public geography, the publics which such geographies serve, alternative and complementary approaches to social media and the politics of authorship within collective blogs.

\section{What kind of public geography?}

Crampton et al. (2013), in particular, take us to task over what they see as our overly narrow conception of public geography, which they argue focuses not on meaningful public participation and engagement, but on the public reception of our viewpoints and data. Their contention is that IrelandAfterNAMA is used primarily as a means of 'pushing' out ideas and opinions from the academy - it is a new channel of broadcast that complements more traditional journal publishing, but it is not a radical departure in the power dynamic. Analysis and knowledge is conceived and produced by academics and the public is expected to listen, digest and change their opinions, with perhaps the occasional expressed reflection in the form of a comment. They rightly note our ambivalence and complaints when the public reaction to our work started to drive our research agenda as our control slipped and became increasingly shaped by the public. They suggest that a public geography rooted in participation and collaboration, in which the public are more actively engaged in setting out what kinds of information and knowledge would be of use and benefit to them, would be a more truly public undertaking. It would also be more empowering and emancipatory in nature. They go on to argue that 'Web 2.0 is not the only, or even the most effective way for geographers to engage with the public to influence policy, or to advocate for social justice. Geographers might just as well spend their limited time participating in community meetings, direct action campaigns, or any number of other forms of service or activism.'

In many ways, we agree that the view of public geography set out in our paper is framed as public reception rather than participation. One of our initial aims, after all, was to try and intervene in a public debate dominated by economists. That said, blogs and other social media such as Twitter are much more participatory than traditional publishing in that they do open up two-way channels of dialogue through readers posting comments as opposed to simple broadcast, and they are aimed at a much wider constituency of readers. Moreover, Crampton et al. (2013) are mobilizing a vision of public geography that remains unaffected by disruptions and reconfigurations to political discourse and practice generated by new media. In particular, they posit that different sites of public geography - the community hall, the street and the media - are discrete realms, with their own distinctive politics, within which the community and place are privileged as more authentic sites for political action. However, new media often forms part of a diverse assemblage of practices used to engage publics. In our own case, the blog posts were accompanied by the kinds of activities they detail - attending meetings, giving public talks, engaging directly with policy makers 
and professional groups, advising individuals and groups about particular social issues, briefing journalists and undertaking media engagements. As such, our blogging did not take place independently of other forms of advocacy and activism, and indeed it was often informed by it.

As raised by Pickerill (2013) and Crampton et al. (2013), it is important to question what is meant by the notion of 'public geographies'. Is it something that is 'out there', and which 'we' must engage with in an active and participatory manner? While there is much merit to such approaches, they also present certain challenges. Whom should academics actively engage with? Are public geographies only about supporting particular causes which we agree with or are they about seeking to engage with a wide variety of public perspectives, which often differ widely from our own? As professional geographers and private actors, we seek to both engage in the world and actively understand what is going on around us (Ward, 2007). In a manner which reflects Denis Cosgrove's (1989) dictum that 'geography is everywhere', the overlaps and tensions between the various means in which we interact in the world is important. In this regard, our blog is not only about the manner of engagement with different publics but it also provides a useful insight into the 'geographical imaginations' held by those publics. That these perspectives have often run counter to our own is an important framing element to understanding 'public geographies'.

The wider question here is to what extent does public geography have to be participatory to be truly public? Does traditional academic work expressed through blogs and aimed at a largely non-academic audience constitute a public geography? In our view, it does. For various reasons, related to personal constraints, professional anxiety, political censorship or even location, some academics cannot engage in direct, place-based activism. Moreover, some kinds of activism need to be operated at scales best managed communicatively - think for instance of international campaigns to address human right abuses. Forms of public geographies thus vary widely and our blog is just one model amongst a wide array of potential engagements. At the same time, we agree that academics need to be responsive and open to enrolment that extends beyond debate and which may demand some change in their research agenda. This will not be easy to negotiate, especially given the neoliberal demands with regards to academic activity, but nevertheless should not be simply dismissed as undesirable or unworkable.

\section{Which publics?}

Both Crampton et al. (2013) and Graham (2013) raise the question as to whose and which publics blogs and other social media might engage. They argue that, as with the Internet more broadly, there are digital divides at work with respect to 'who has access to blogs and who can pay attention?' (Crampton et al. 2013). Graham's (2013) maps of Twitter users in two African cities appear on first glance to illustrates this point vividly. However, deploying claims about the digital divide as a brake to making critical interventions through digital praxis is quite problematic. Even in these African cities, the intersection of information and communication technologies (ICT), technology and politics, notably on short message (or messaging) service (SMS) platforms, plays a dynamic role in shaping political discourse as well as enabling a whole range of social and economic activity, such as providing education, healthcare and even - as with the case of mobile money (M-PESA) - currency. SMS platforms are so powerful as media and information providers that they are frequently censored and closed down - notably in Ethiopia during the political crisis following the 2005 election. The question they pose then in terms of challenging the extent to which social media do create 'radical openness' given digital and intellectual divides, and the extent to which those choosing to use social media are inherently self-selecting the kinds of publics with which they seek to engage, requires careful analysis.

There is little doubt that the impacts of IrelandAfterNAMA is bounded to those who have Internet access, those that have the time to read it, those with sufficient literacy and knowledge to engage with the arguments made, and those that are interested in thinking more critically about the crisis affecting the country. The same is undoubtedly the case with respect to media such as newspapers, books, radio, television, public meetings, conferences and so on. 
There are always divides concerning access to the media and the intended audience. That said, social media is radically more open than the traditional means of academic communication - expensive books and journal articles in academic libraries or behind online pay walls that inherently limit access. It is also the case that over the long-term, the blog will act as an archive and as an information and learning resource, which will be accessed in the future. Moreover, for all of those who do have Internet access, it does not overly circumscribe the audience as anyone is free to read and comment on the articles. Nevertheless, we agree that those using social media need to be mindful of which publics they are seeking to engage, and which are excluded from the debate.

\section{The politics of authorship}

Davies (2013) in his response raises a different issue with respect to the creation of public geographies, that of the politics of authorship. He rightly notes that blogging is embedded in a set of social relations that actively shapes what is written and by whom. Traditional publishing is replete with gatekeepers who manage the publishing process and make decisions about what work is disseminated. Blogs are not entirely free from such gatekeeping, especially collective blogs where there might be a set of editors that vet postings. Even with individual blogs, at the back of the poster's mind is how the post might be received by colleagues and managers within their peer network and institution. We thus agree with Davies' (2013) assessment that blogs should not be viewed as "new "ideal" spaces for democratic deliberation'; they are not free of the politics of publishing. At the same time, blogs as Graham (2013) notes are largely produced within unsupportive systems of governance - a license of academic freedom broadly operates that enables a writer to express their views, not withstanding any editorial oversight. As such, blogs at present have not been captured by the academic 'sausage factory' (Smith, 2000), but as Gibson and Gibbs (2013) note, this could alter as they slowly drift towards becoming another mainstream form of academic authorship: 'another space where the evils of competitive individualism, university corporatism, metrics micro-management and bullying are amplified'. But, as they go on to argue, such a fate is not predestined. There is the potential for social media to function as a 'more communitarian vision of academic life, a mode of knowledge production that is generous, supportive, and engages at multiple points in the development of ideas'.

As Pickerill (2013) and Gibson and Gibbs (2013) note in their commentaries, the politics of authorship and the production of knowledge, along with digital divides that operate across the globe, open up questions about the geography of geographers who blog, where they blog about, and the geography of the production of knowledge. We have not examined the geography of geography blogging per se and given our own tacit knowledge is limited to Anglo-American geography, it is difficult to comment. However, we do agree that it would be interesting to plot the geography of the disciplinary social media landscape and, as Pickerill (2013) notes, to think through its implications. Gibson and Gibbs (2013) give some initial observations, suggesting that social media has helped to erode Anglo-American hegemonies in the production of knowledge by enabling geographers on the periphery 'to overcome geographical marginality, improve (virtual) proximity to other academic hubs, and generate new and different kinds of political and intellectual allegiances'. They go on to argue that '[t]he social media assemblage certainly has no central head. Viewed from the Antipodes, that in itself is a positive shift. But what are also important are the coming together of things, the forming and reforming of relations, the shifts over time. Isolation and anonymity feel negotiable, if not altogether overcome'

While this is a welcome observation, the decentralising and deterritorizing nature of social media - or centripetal and centrifugal processes in Graham's (2013) terms - should not be over-stated. Academic organisation, practices and hegemonies are still very much in operation and are resistive to change. Drawing on our own and the observations in the commentaries, it is clear that blogs are best understood as negotiated, contested spaces that unfold within a contingent and political set of relations, but relations that, at present, are more open than traditional forms of publication but whose openness is not guaranteed. It is certainly the case then that how social media 
work to shape the production of knowledge needs further unpacking.

\section{Politics of knowledge circulation}

In addition to thinking about the creation of public geographies, the commentaries also raise important questions concerning the politics and mechanisms of knowledge circulation and the extent to which social media has an impact beyond the academy, enacting 'minimal politics'.

\section{How knowledge circulates}

Beer (2013), in his commentary, makes a number of useful points about how social media changes the way in which academic knowledge circulates and does work in the world. He notes the ways in which blogs find out their audiences - what Weinberger (2011) calls 'filtering forward' - wherein the tags and content is harvested by search engines and is pushed and shared through tweets, Facebook, traditional media, rather than a reader tracking down a piece that might of interest to them. He argues that such filtering forward means that the posts reach a more diverse audience than academic work traditionally does, and that is therefore more likely to take on a livelier life of its own. This he surmises is one of the reasons underpinning some of the anxieties of academics who blog; that the work is taken out of the carefully controlled and protected world of traditional publishing and placed in a medium where it is more easily misinterpreted, misrepresented and mis-used and can attract unwanted critical attention. Blog posts are more 'vital, vibrant and lively'. Crampton et al. (2013) put it a slightly different way: ' $[\mathrm{h}] \mathrm{ow}$ much of these hesitancies are about premature conclusions, and how much is about protecting our public image and credibility?' It is certainly the case that using social media does change the public image of academics, placing them in dialogue which a broader constituency than they have traditionally conversed. For Beer (2013), this requires 're-imagining of our audiences, what we might say to them and how we might say it'. It also requires, as Graham (2013) contends, thinking though the complex online power-geometries of those audiences and how knowledge is shared and critiqued amongst them. In this regard, contributors to IrelandAfterNAMA learned to mitigate certain misinterpretations of their posts by writing more clearly and unambiguously, but, more importantly, they also learned to divest a certain level of control over how and where their work was re-contextualised.

As yet, collectively, we have not sought to systematically discover the ways in which our posts and views have circulated, and how they have been engaged with and reworked and re-employed, beyond seeking to track in rather functional ways how some of the information was picked up by the media and anecdotally noting particular interactions. It is clear that much more research needs to be undertaken with regards the social and spatial processes by which knowledge circulates and mutates through social media, its intersections with other fora such as broadcast media, meetings, classrooms, pub talk, and so on, and how tokens of credibility, authority and reputation are recast and negotiated. Within such research, attention clearly needs to be paid to the extent to which knowledges effect change and enact minimal politics and the degree to which these are shaped, or even censored, by software assemblages and other non-human processes.

\section{Impact and minimal politics}

There is no doubt that we were hoping that IrelandAfterNAMA might have some form of impact in contributing to public debate in Ireland. Our ambitions were modest and we were fortunate that our posts were picked up by journalists looking for a different perspective. We know too that the blog has been used by our students - and has thus made some contribution to a critical pedagogy. Beer (2013) is undoubtedly right, however, that the initial and on-going problem with blogging is 'how to get heard and how to make yourself visible above the cultural cacophony', especially given the absence of the gatekeeping credibility that journals provide new authors. Some of our posts disappear without a trace, viewed by just a handful of readers and uncommented upon. They failed to enact our hope of minimal politics. At least, it seems, for now. Who knows what role they may 
play in the future, as they are archived and redistributed. But unlike Crampton et al.'s (2013) desire for more than minimal politics, we are of the view that that is all we can expect and strive for - small interventions in a complex public-sphere. Not to speak, staying silent and cultivating our academic careers through prestige publications and so on, whilst our neighbours, families and friends paid the cost of an economic crisis, would have been intolerable. And we do feel that such minimal politics do make for a public geography, in the sense that they engage publics and are for the public.

As Davies (2013) notes, the notion of minimal politics may constitute a productive middleground in the quandary broached in the debates on post-politics between agonistic and deliberative politics. As Barnett (2013) points out (in a blog post Davies (2013) cites in his commentary), 'in trying to think about politics and change, it might be better to look ahead rather than constantly look backwards'. In this sense, the way that social media which as Graham (2013) suggests 'already form a significant part of the ways in which many people understand their social, political, economic, and environmental contexts' - may function as a conduit for political action can be constructive in conceptualising the role of minimal politics. If, as Davies (2013) argues, most blogs are marginal spaces, the relational assemblages enabled by the 'politics of circulation' enable a potentiality, albeit unpredictable, for blogs to affect the media landscape in ways that far outweigh their nominal significance, at least in particular instances. As many of the commentaries point out, however, the Internet is by no means an open, egalitarian, and uncontested space, nor does it exist in a utopian vacuum hermetically sealed from the political economy that encircles it and actively creates it. Nevertheless, in line with Ranciere's 'emancipated spectator', social media users have a certain agency in their reception (and recontextualisation) of content. As Rancière (2009: 13) puts it:

Emancipation begins when we challenge the opposition between viewing and acting ... It begins when we understand that viewing is also an action that confirms or transforms this distribution of positions. The spectator also acts, like a pupil or a scholar. She observes, selects, compares, interprets. She links what she sees to a host of other things that she has seen on other stages, in other kinds of place ... She particulates in the performance by refashioning it in her own way ...

Without getting caught in a techno-utopian trap, it would seem that social media platforms provide new types of mechanisms and opportunities for the types of spectatorship that Rancière has in mind. A similar argument is also made by Purcell (2013: 12-14) when he reminds us that 'constituent power' (the agency of the multitude) is always primary to the 'constituted power' (of states or other such authorities) and that the former ' $\ldots$ is always present, always operating, always driving the process of change'. We do not, however, have much of a handle on the nature of minimal politics as yet and Davies (2013) is right to suggest that much more thinking needs to be done with respect to the political work that blogs do, what they do that is different to other media, 'how they add to our repertoires of political behaviour, and in what areas are they useful when compared to 'older' forms of political behaviour'.

\section{Reimagining the academic landscape}

Our own paper and the commentaries make a case that social media is providing a new form of communication that enables a reimagining and reconfiguring of the academic landscape. For Beer (2013), it presents 'powerful opportunities for rethinking the 'craft' of social research.' For Graham (2013), blogging has changed who he writes for, who he thinks he should write for, and has altered what it means to be a geographer and academic. For Gibson and Gibbs (2013), it has produced a new form of collegiality, enabled the formation of new alliances, created new interactions, and partially over-coming geographic peripherality. All agree that social media is transforming the practices of geographic knowledge production - how knowledge is produced, for whom, how it is circulated and consumed, and how it does work in the world in terms of fomenting political and other kinds of action. That said, as Graham (2013) notes, the core governance 
mechanisms of academy, and academic funding, research and dissemination, have a deep institutional embeddedness that resists radical change. How the effects of social media are and will play out then is not predetermined, but will unfold in uneven, unequal and contested ways. The aim of paper was to draw upon our own experiences to start to map such changes and tensions out. As the commentaries and we have noted here, there is a lot more thinking to be done, much of which will undoubtedly take place through social media.

\section{References}

Barnett C (2013) Varieties of 'the political'. Pop Theory, http://clivebarnett.wordpress.com/2013/02/11/varietiesof-the-political/ (accessed 12 January 2013).

Beer D (2013) Public geography and the politics of circulation. Dialogues in Human Geography 3(1). doi: 10. 1177/2043820613486427.

Cosgrove D (1989) Geography is everywhere: culture and symbolism in human landscapes. In: Gregory D and Walford R (eds) Horizons in Human Geography. London, UK: Palgrave Macmillan.

Crampton JW, Bowen J, Cockayne D, Cook B, Nost E, and Shade L (2013) Whose geography? Which publics? Dialogues in Human Geography 3(1). doi: 10. $1177 / 2043820613486428$.
Davies A (2013) Blogs as 'minimal' politics. Dialogues in Human Geography 3(1). doi: 10.1177/2043820613 486429.

Gibson C and Gibbs L (2013) Social media experiments: Scholarly practice and collegiality. Dialogues in Human Geography 3(1). doi: 10.1177/2043820613486430.

Graham M (2013) Social media and the academy: New publics or public geographies? Dialogues in Human Geography 3(1). doi: 10.1177/2043820613486431.

Kitchin R, Linehan D, O'Callaghan C and Lawton P (2013) Public geographies through social media. Dialogues in Human Geography 3(1). doi: 10.1177/ 2043820613486432.

Pickerill J (2013) Review comments on 'public geographies through social media'. Dialogues in Human Geography 3(1). doi: 10.1177/2043820613486436.

Purcell M (2013) The Down-Deep Delight of Democracy. Oxford, UK: Wiley Blackwell.

Smith N (2000) Afterword: who rules this sausage factory? Antipode 32: 330-339.

Rancière J (2009) The Emancipated Spectator. London, UK: Verso.

Ward K (2007) Geography and public policy: activist, participatory, and policy geographies. Progress in Human Geography 31(5): 695-705.

Weinberger D (2011) Too Big To Know. New York, NY: Basic Books. 